\title{
Varying Responses of Cultured Mammalian Cell Lines to the Cellular DNA Breaking Activity of Epinephrine
}

\author{
Koji Yamada, Hiroki Murakami, Hisashi Nishiguchi, Sanetaka Shirahata, \\ Kazuki SHINOHARA and Hirohisa OMURA
}

\author{
Department of Food Science and Technology, Faculty of Agriculture, \\ Kyushu University \\ Received June 19, 1978
}

\begin{abstract}
To clarify the mechanism of cellular DNA breakage with epinephrine (Ep), the relationship between the activities of ${ }^{1+} \mathrm{C}$-Ep incorporation and DNA breakages was studied by the use of three cultured cell lines: rat fetal lung, HeLa-S3 and L. Rat fetal lung cells which were the most sensitive to the lethal effect of Ep showed more remarkable incorporation of the radioactivity than the other cell lines and both single-strand and double-strand breaks were detected upon treatment with $25 \mu \mathrm{M} \mathrm{Ep}$. This parallel relationship between the ${ }^{14} \mathrm{C}$-Ep incorporation and the cellular DNA breaking activity of Ep suggests that the cellular DNA is broken by a direct attack of Ep on DNA and the development of the reaction is dependent on the cell line.
\end{abstract}

Reductones contained in foodstuffs or produced during food processing can break DNA $^{1,2)}$ and have various biological activities such as antitumor potentiality. ${ }^{3 /}$ Among them, catecholamines such as epinephrine (Ep) break chromatin DNA of cultured mammalian cells to bring about changes in the activities of some enzymes, the rate of DNA synthesis and the sensitivity to murine leukemia virus. ${ }^{\text {* }}$ This ability to break cellular DNA varies with not only the species of the amines but also the lines of cultured cells., ${ }^{4,5}$ It has been believed that catecholamines develop their functions as hormones and/or neurotransmitters through their binding to cellular membrane and activation of adenyl cyclase. ${ }^{8)}$ However, ${ }^{14} \mathrm{C}-\mathrm{Ep}$ added to the culture medium was quickly incorporated into rat fetal lung (RFL) cells and about $50 \%$ of $\mathrm{Ep}$ incorporated was detected in the DNA fraction. ${ }^{71}$ This suggests a possibility that the DNA breaking reaction and a part of hormonal actions of this amine can be performed through its direct attack on chromatin DNA. To elucidate the difference among cell lines in sensitivity to the amine, three mammalian cell lines-RFL, HeLa-S3 (HeLa) and L-were compared in this study with respect to resistance to $\mathrm{Ep}$, ability to incorporate ${ }^{14} \mathrm{C}-\mathrm{Ep}$ and activity of $\mathrm{Ep}$ on cel- lular DNA breaking.

\section{MATERIALS AND METHODS}

Determination of cellular propagation rate. RFL, HeLa and $\mathrm{L}$ cells were all maintained in Eagle MEM (Nissui No. 1) supplemented with $10 \%$ bovine serum and $0.029 \%$ glutamine. Each cell line was cultured in a stoppered flask at $38^{\circ} \mathrm{C}$. The cells were attached on the glass surface and propagated to form a cell sheet. Doubling periods of the cell lines were 26,26 and $28 \mathrm{hr}$, respectively. Growth rates of these cells treated with various concentration of $\mathrm{Ep}$ were obtained by the method previously described. ${ }^{\text {s) }}$

Centrifugal analyses of cellular DNA breakage. Cells which had had their DNA labeled with ${ }^{3} \mathrm{H}$ thymidine $(20 \sim 30 \mathrm{Ci} / \mathrm{mmol})$ were treated with varying concentration of Ep for $6 \mathrm{hr}$. Alkaline or neutral sucrose density gradient solution on which the cells were lysed with alkali or SDS (sodium dodecyl sulfate) was centrifuged. Distribution of tritiated DNA in a centrifugal tube was then measured. Methods of DNA labeling, Ep treatment of cells and centrifugal analyses of cellular DNA were previously descrived in detail.4)

Detection of subcellular distribution of ${ }^{14} \mathrm{C}$-epinephrine. Each cell line $\left(5 \times 10^{5}\right.$ cells $)$ was inoculated in a 5 -ml culture flask. After incubation for $16 \mathrm{hr}$ at $38^{\circ} \mathrm{C}$, the culture medium was replaced with another containing $0.1 \mu \mathrm{Ci} / \mathrm{ml}{ }^{14} \mathrm{C}-\mathrm{Ep}$ (NEC-547, $16.9 \mathrm{mmol} /$ Ci) and then the cells were incubated for 6 more hr to tag cellular components with the radioactive compound. Then the medium was discarded and the cell sheet was 
rinsed with three 5-ml portions of phosphate buffered saline (PBS, pH 7.4). Cells were dispersed from the sheet with $5-\mathrm{ml}$ trypsin solution $(200 \mathrm{HUM} / \mathrm{ml})$ and collected by centrifugation for $5 \mathrm{~min}$ at $1.500 \mathrm{rpm}$. The cell pellet thus obtained of was resuspended in 2-ml PBS to count the number of cells. Then, $1 \mathrm{ml}$ of $2 \%$ SDS was added to an equal volume of the cell suspension to disrupt the cells by denaturation of cellular proteins. An equal volume of $2 \mathrm{M} \mathrm{NaCl}$ solution was added to the lysate to precipitate the denatured proteins. The mixture was allowed to stand for $1 \mathrm{hr}$ at $0^{\circ} \mathrm{C}$ to complete salting-out of the proteins, followed by centrifugation for $10 \mathrm{~min}$ at $3,000 \mathrm{rpm}$ to remove the proteins. Chromatin DNA in the supernatant was separated by adding an equal volume of cold ethanol. Each fraction was lyophilized and then dissolved in $\mathrm{N} \mathrm{NaOH}$. An aliquot was suspended in a $10-\mathrm{ml}$ toluene-ethanol $(3: 2)$ scintillator to measure the radioactivity with a Beckman 250 Liquid Scintillation Counter. The counting efficiency was culculated to be $50 \%$.

\section{RESULTS AND DISCUSSION}

\section{Effect of epinephrine on cell propagation}

Each cell line was incubated for $6 \mathrm{hr}$ at $38^{\circ} \mathrm{C}$ with a medium containing varying concentration of Ep. After the medium was replaced with one without $\mathrm{Ep}$, the cells were further incubated to count the number of cells periodically. The rate of propagation of each cell line is shown in Fig. 1. RFL cells were the most sensitive among these cells. The cellular propagation was little affected in $25 \mu_{\mathrm{M}} \mathrm{Ep}$, but completely inhibited in $250 \mu \mathrm{M}$ Ep though the latter concentration showed little cytocidal action. At such a higher concentration of Ep as $2,500 \mu \mathrm{M}$, all the cells were judged to be dead within $6 \mathrm{hr}$, since the treatment resulted in loss of adhesiveness of the cells to the glass surface.

HeLa cells were more resistant to Ep treatment than RFL cells. In the presence of $25 \mu \mathrm{M}$ $\mathrm{Ep}$, the cells could propagate nearly as vigorously as untreated control cells. A higher concentration of Ep such as $250 \mu \mathrm{M}$ elicited an $18 \%$ decrease in the rate of cellular propagation after $48 \mathrm{hr}$. In $2,500 \mu \mathrm{M}$ Ep the viable cell number was gradually reduced, down to $50 \%$ of the initial value after a 48 -hr incubation.

On the other hand, L cells were the most

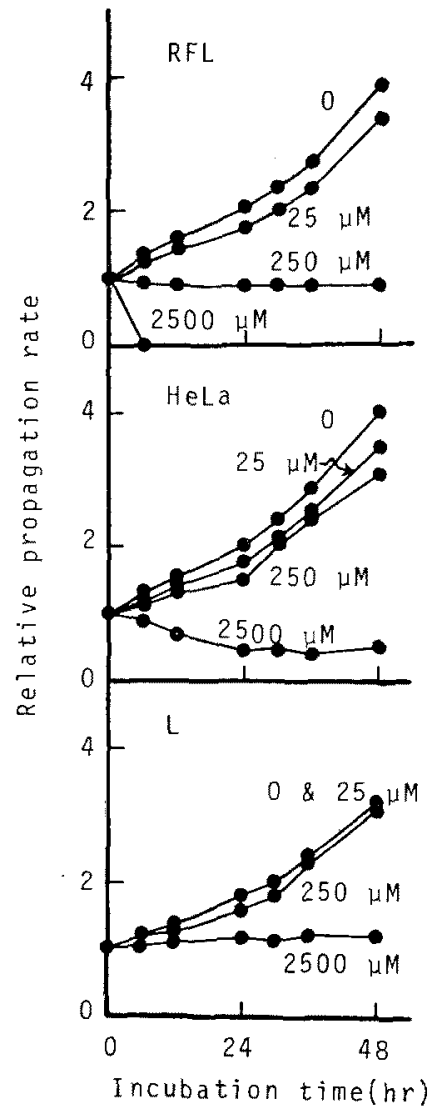

Frg. 1. Effect of Varying Concentrations of Epinephrine on the Propagation of Cell Lines.

Each cell line was cultured in the Eagle MEM medium containing varying concentrations of $\mathrm{Ep}$. Cell numbers were counted periodically.

resistant among the three cell lines. The propagation of this line was scarcely inhibited even in the presence of $250 \mu \mathrm{M} \mathrm{Ep}$. This cell line had such a high resistance to Ep that even the highest concentration of Ep tested, 2,500 $\mu \mathrm{M}$, proved not cytocidal but only cyto-static.

From these results it is obvious that RFL cells were ten times as sensitive as other two cell lines, and that $\mathrm{L}$ cells can survive the highest concentration of the drug tested.

\section{Ultracentrifugal detection of cellular DNA breakages}

As shown above, sensitivity of cellular viability to Ep treatment varied with cell lines. Sucrose density gradient $(5 \sim 20 \%)$ centrifugal analyses of cellular DNA were carried out 
under both alkaline and neutral conditions to compare the extent of the DNA breakage deriving from Ep treatment. Under an alkaline condition, single strand breakages (SSB) occurring in the DNA was detectable and its double strand breakages (DSB) could be measured by neutral sucrose gradient centrifugation. However it was difficult to estimate the correct number of DNA breakages, especially under a neutral condition. Although the molecular weight of cellular DNA is estimated at between $10^{10}$ to $10^{12}$ daltons, ${ }^{14}$ ) its net molecular weight was too massive to measure. Thus, the DNA breaking action of Ep was studied only qualitatively. Ultracentrifugal profiles of tritiated DNAs deriving from RFL, HeLa and $L$ cells which had been treated with varying concentration of $\mathrm{Ep}$ are shown in figures 2,3 and 4 , respectively. In the left panels (A series) of these figures, the results under the alkaline condition, and in the right panels ( $\mathrm{N}$ series), the profiles under the neutral condition are shown.

Sedimentation patterns of untreated RFL cellular DNA under both alkaline and neutral

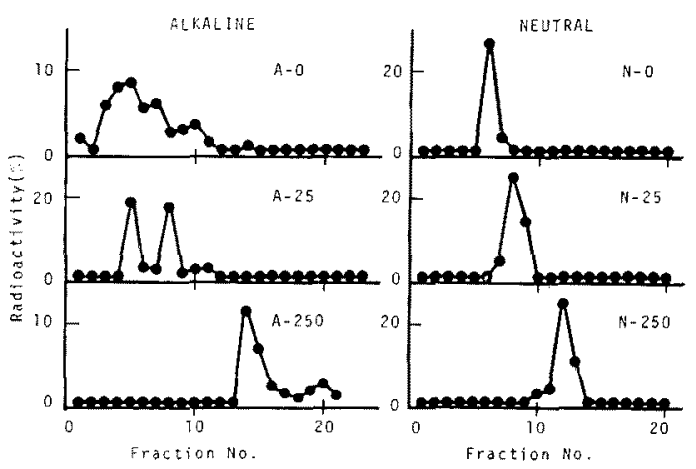

Fig. 2. Sedimentation Profiles of RFL Cellular DNA Treated with Varying Concentrations of Epinephrine.

Cells were incubated in the Eagle MEM containing $0(0), 25 \mu \mathrm{M}(25)$ or $250 \mu \mathrm{M}$ (250) epnephrine at $38^{\circ} \mathrm{C}$ for $6 \mathrm{hr}$. Then the cells were harvested to be suspended in PBS and about $10^{4}$ cells in $0.2 \mathrm{ml}$ PBS were put on an alkaline (on the left panel) and a neutral (on the right panel) sucrose gradient. Centrifugation was carried out for $1 \mathrm{hr}$ at 20,000 rpm under alkaline and at $30,000 \mathrm{rpm}$ under neutral conditions. Similar descriptions and an analytical method were also used in the experiments of both Figs. 3 and 4 . conditions (A-0 and $\mathrm{N}-0$ in Fig. 2) shifted to those described in A-25 and N-25 upon treatment with $25 \mu \mathrm{M}$ Ep. This Ep concentration was little affected the viability of the cells which could propagate similarly to untreated control cells. Consequently, it is obvious that DSB occurring in the cellular DNA was not necessarily cytocidal as was the case with UV irradiated cells. ${ }^{8}$, On treatment with 250 $\mu \mathrm{M}$ Ep, which completely inhibited the propagation of the cells, both types of breakages occurred so extensive ( $\mathrm{A}-250$ and $\mathrm{N}-250$ ) that the DNA fragment sedimented more slowly. We have already shown that DSB which occurred extensively was cytocidal, but some DSB could be repaired and the partial rejoining of the ability of cellular DNA was closely related to the restoration of the ability of cellular propagation by the use of RFL cells treated with 3,4-dihydroxyphenylglyoxime (DPG). . $^{\text {? }}$ It has also been confirmed that RFL cells preserving DSB can propagate as fast as normal cells, ${ }^{4,5,8)}$ but the extent of DSB which is critical to the propagation has not yet been clarified.

The results obtained from the centrifugal analyses of HeLa cellular DNA are summarized
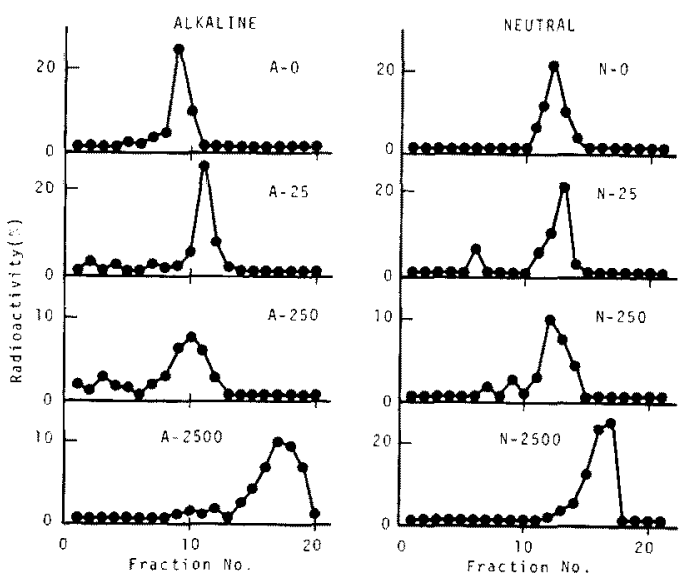

Fig. 3. Sedimentation Profiles of Intracellular DNA of HeLa Treated with Varying Concentrations of Epinephrine.

Cells were cultured in the medium containing $0 \mu \mathrm{M}(0)$, $25 \mu \mathrm{M}(25), 250 \mu \mathrm{M}(250)$ or $2,500 \mu \mathrm{M}$ (2500) epinephrine at $38^{\circ} \mathrm{C}$ for $6 \mathrm{hr}$, followed by ultracentrifugal analyses using both alkaline and neutral sucrose gradients. 

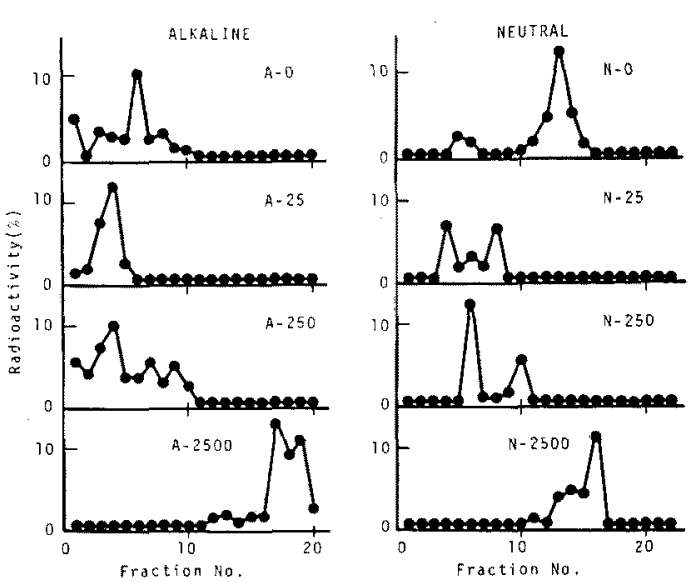

FIG. 4. Sedimentation Profiles of L Cellular DNA Treated with Varying Concentrations of Epinephrine. Cell were cultured in the medium containing $0 \mu \mathrm{M}(0)$, $25 \mu \mathrm{M}$ (25), $250 \mu \mathrm{M}$ (250) or 2,500 $\mu \mathrm{M}$ (2500) epinephrine at $38^{\circ} \mathrm{C}$ for $6 \mathrm{hr}$ and then analyzed.

in Fig. 3. This cell line received neither SSB (A-25 or A-250) nor DSB (N-25 or N-250) even in 25 or $250 \mu \mathrm{M}$ Ep. Both strand breakages were first detected in the cells which had been treated with $2,500 \mu \mathrm{M} \mathrm{Ep}$, which killed $50 \%$ of the cells within $6 \mathrm{hr}$.

Sedimentation profiles of L-DNA are shown in Fig. 4. Profiles of alkaline sucrose density gradient of L cellular DNA treated with $25 \mu \mathrm{M}$ (A-25) and $250 \mu \mathrm{M}(\mathrm{A}-250)$ Ep surprisingly revealed that the single strand DNA of the treated cells sedimented more rapidly than that of the untreated control. Sedimentation velocity in A-25 was slightly greater than that in A-250. Since sedimentation velocity is correlated unequivocally with the chain length of single strand DNA, the results obtained suggest that the recombination of DNA molecules ocurrs by the treatment of $\mathrm{L}$ cells with 25 and $250 \mu \mathrm{M}$ Ep. Elongation of single strand DNA reflects an increase in sedimentation velocity of DNA in the neutral condition. Similar result had been obtained by the use of RFL cells treated with 3', 4'-dihydroxy-2'nitroso-2-(methylamino)acetophenone, ${ }^{5)}$ and it was sometimes seen that even $25 \mu \mathrm{M} \mathrm{Ep}$ which is a DNA breaking reagent induced an increase in sedimentation velocity of the cellular DNA. These results evidently indicate that elongation of the DNA results from the ligation of double strand DNA fragments which have been split by the treatment with catecholamines and have cohesive end to adhere to other DNA fragments. In this process of mutual ligation of DNA fragments, the DNA produced by the ligation is still shorter than the original cellular DNA. On the other hand, if the cellular DNA sustains a weak breaking action to produce rather large fragments should be larger than the cellular DNA. This assumption was certainly substantiated by the finding that $\mathrm{L}$ cellular DNA treated with 2,500 $\mu \mathrm{M}$ Ep existed as shorter molecules (A-2,500 and $\mathrm{N}-2,500$ in Fig. 4), since a higher concentration of Ep brought about more breaks to shorten the DNA strands though the DNA was elongated significantly by $25 \mu \mathrm{M}$ Ep and slightly by $250 \mu \mathrm{M}$ Ep. Then, it is also concluded that apparent changes in molecular size of cellular DNA treated with catecholamines result from the combinated effect of the DNA breaking activity of the drugs, cellular susceptibility to the reaction and DNA-ligating potency of the cells. Though we cannot regulate the DNA-ligating potency of the cells satifactorily, the potency is known to be enhanced by the addition of dibutiryl cyclic AMP, ${ }^{10}$ which is an inhibitor of phosphodiesterase, to RFL cells after their treatment with $25 \mu \mathrm{M}$ Ep.

\section{Incorporation of ${ }^{14} \mathrm{C}$-epinephrine into subcellular fractions}

It is already found that ${ }^{14} \mathrm{C}$-Ep added to the culture medium is incorporated into RFL cellular nuclei, ${ }^{7}$ that DNA breaking reaction with aromatic reductones is closely related to the oxidation of the latter ${ }^{11,12}$ and that Ep bound to nucleosome is easily oxidized. ${ }^{13}$ ) On the basis of these findings, it was assumed that the breaking reaction of cellular DNA would take place with the oxidation of $\mathrm{Ep}$, which could be incorporated into the nuclei and oxidized by interaction with chromatin. Thus the intracellular distribution of $\mathrm{Ep}$ in three cell lines was studied after incubation at $38^{\circ} \mathrm{C}$ for $6 \mathrm{hr}$ in a medium containing $0.1 \mu \mathrm{Ci} /$ $\mathrm{ml}{ }^{14} \mathrm{C}$-Ep. The results are summarized in 
TABLE I. INCORPORATION OF ${ }^{14} \mathrm{C}$-EPINEPHRINE INTO SUbCELlULAR Fractions OF THREE CELL LiNES

Each fraction was prepared by the method described in the text from three cell lines.

\begin{tabular}{|c|c|c|c|c|c|c|}
\hline & & & tivity in & & & \\
\hline Subcellular & & & & & & \\
\hline & $\mathrm{cpm} /$ & $\%$ & $\mathrm{cpm}$ & $(\%)$ & $\mathrm{cpm} / 1$ & \\
\hline Whole cells & 14,300 & 100 & 2,837 & 100 & 3,250 & 100 \\
\hline Trypsin sup. & 2,400 & 17 & 805 & 28 & 1,580 & 49 \\
\hline Trypsinized cells & 11,900 & 83 & 2,032 & 72 & 1,670 & 51 \\
\hline Protein & 6,300 & 44 & b.d. & - & 491 & 15 \\
\hline DNA & 4,100 & 29 & b.d. & -- & b.d. & - \\
\hline Soluble & b.d. & - & 1,916 & 68 & 1,315 & 40 \\
\hline
\end{tabular}

b.d.: Below the limit of detection.

Table I.

Cells treated with ${ }^{14} \mathrm{C}$-Ep were stripped off the glass by trypsin treatment. Radioactivity in whole cells was calculated by adding the activities in both the trypsin solution (trypsin sup.) and trypsinized cells. Radioactivity in trypsin sup. corresponded to Ep adsorbed on the cell surface. Consequently, the activity in trypsinized cells represented the substance incorporated inside the cells. The activity in the protein fraction corresponded to that of protein bound Ep, and free Ep or Ep bound to low-molecular components such as RNA in the cells was detectable in the soluble fraction.

RFL cells uptook a large amount of Ep, compared with other cell lines tested. Most $(83 \%)$ of the Ep was incorporated into the cells. In the DNA, $29 \%$ of the total radioactivity uptaken was detected. Since the radioactivity of DNA did not decrease when it was further treated with $90 \%$ phenol to remove residual proteins, Ep should be bound to DNA itself. ${ }^{7)}$ Free Ep was meager in the cells since no detectable amount of the radioactivity was measured in the soluble fraction and $44 \%$ of the total activity derived from that of protein bound Ep.

RFL cells used in this series of experiments showed a less Ep incorporative activity than that tested previously. ${ }^{7}$ Although there was no great discrepancy in radioactivity level between trypsin sup. and trypsinized cells, the ratio of protein-bound Ep to Ep in DNA was considerably inconsistent. Since the amount of Ep bound to protein did not increase, this may be due to a decrease in binding of Ep to DNA. Such a fluctuation of ${ }^{14} \mathrm{C}-\mathrm{Ep}$ incorporation suggests that incorporation of exogenous Ep into RFL cells is dependent on the cellular physiological condition. The study using synchronous culture of the cells is under way to clarify the problem.

Ep incorporated into HeLa cells resided predominantly in the soluble fraction, indicating the absence of proteinous substance which could bind Ep in these cells. In the DNA portion no radioactivity was detected. These findings suggest that the binding reaction of Ep to DNA may be mediated by Ep binding protein.

In the $\mathrm{L}$ line, $51 \%$ of total Ep was incorporated into the cells. Although $15 \%$ of Ep existed in a state of protein-bound type: no appreciable amount of Ep was found in the DNA fraction. Under the experimental con. ditions employed, however, Ep below p moles which correspond to $10^{5} \mathrm{Ep}$ molecules in a cell was not detectable. Thus, we can not deny that fairly large numbers of Ep molecule: exist in the vicinity of $\mathrm{L}$ cellular DNA, sinct Ep binding protein can be detected in the cel line.

From the findings obtained through a serie of experiments described above, it is now re alized that the DNA breaking reaction so muc] varies with the cell line. The extent of DNt breakage seems to be correlated with the con centration of $\mathrm{Ep}$ incorporated into the cells 
and this suggests that Ep can be directly responsible for the breakage of intracellular DNA. In the case of in vitro experiments, Ep can break DNA only in the presence of $\mathrm{Cu}^{2+}$. Although it is unknown whether $\mathrm{Cu}^{2+}$ in the DNA molecules $\left(140 \mu \mathrm{g} / \mathrm{mg} \mathrm{DNA}^{15}\right)$ is sufficient to oxidize Ep and to break cellular DNA in cultured mammalian cells, calf thymus chromatin and its DNase II digest did oxidize Ep. ${ }^{131}$ Thus Ep added to the culture medium was incorporated into nuclei and might break cellular DNA, when it was oxidized by chromatin. The in vitro mechanism of this DNA breaking reaction by Ep will be disscussed elsewhere in relation to the mode of Ep binding to DNA.

Furthermore, it is concluded that ultracentrifugal profiles we have obtained are based on the combined reactions of DNA breaking reaction with Ep and DNA-ligation with intracellular system. Consequently, the elongation of the DNA should be understood as an event following the DNA breaking reaction with Ep.

Acknowledgment. This work was supported in part by Scientific Research Grant No. 21106 from the Ministry of Education, Science and Culture of Japan.

\section{REFERENCES}

1) H. Murakami and K. Yamafuji; Enzymologia, 38 337 (1970).
2) H. Omura, S. liyama, Y. Tomita, Y. Narazaki, K. Shinohara and H. Murakami, J. Nutr. Sci. Vitaminol., 21, 237 (1975).

3) K. Yamafuji, H. Murakami and M. Shinozuka, Z. Krebsforsh., 75, 55 (1970).

4) H. Murakami, T. Miyoshi, M. Koga, K. Yamada and H. Omura, Agric. Biol. Chem., 39, 795 (1975).

5) H. Murakami, K. Yamada, S. Shirahata, H. Nishiguchi, K. Shinohara and H. Omura, Agric. Biol. Chem., 42, 1019 (1978).

6) G. Robinson, R. Butcher and E. Sutherland, "Cyclic AMP", Academic Press Inc., New Yorkand London, 1971, p. 23.

7) H. Murakami, K. Yamada, S. Shirahata, K. Shinohara and H. Omura, Agric. Biol. Chem., 42, 45 (1978).

8) H. S. Kaplan, Proc. Natl. Acad. Sci., USA, 55, 1442 (1976).

9) H. Murakami, T. Miyoshi and H. Omura, $J$. Fac. Agr., Kylıshu Univ., 18, 149 (1974).

10) H. Murakami, T. Miyoshi and H. Omura, The 50th Antual Meeting of the Agric. Biol. Chem. Soc., Japan, Tokyo, April, 1974, p. 352.

11) S. Shirahata, H. Murakami and H. Omura, Sci. Bull. Fac. Agr., Kyushu Univ., 29. 1 (1974).

12) H. Murakami, S. Shirahata, K. Yamada and H. Omura, Nippon Nogeikagaku Kaishi, 49, 401 (1975).

13) H. Murakami, K. Yamada, H. Nishiguchi, S. Shirahata, K. Shinohara and H. Omura, to be published.

14) T. Terashima and A. Tuboi, Biochim. Biophys. Acta, 174, 309 (1969).

15) W. Wacker and B. Vallee, J. Biol. Chem., 234, 3257 (1959). 